\title{
A New Process for the Production of Coenzyme $A^{\dagger}$
}

\author{
Sakayu Shimizu, Keijiro MiYata," Yoshiki TanI \\ and Koichi Ogata \\ Department of Agricultural Chemistry, Kyoto University, Kyoto \\ *Technical Department of Wakamoto Pharmaceutical Co., Ltd., Kanagawa
}

Received September 12, 1972

\begin{abstract}
A new process has been described for the preparation of coenzyme A of high purity from the cultured broth of Brevibacterium ammoniagenes IFO 12071. The product was obtained in a high yield by the use of Duolite S-30, charcoal, and Dowex $1 \times 2$, and identified chemically and enzymatically. This method is simple, rapid, and compact, requires no special equipment, and has been shown to be adaptable for preparing large amounts of highly pure coenzyme A.
\end{abstract}

The authors have previously reported the isolation of coenzyme $\mathrm{A}(\mathrm{CoA})$ in a high yield from a reaction mixture of dried cells of Brevibacterium ammoniagenes IFO 12071 by the use of charcoal and DEAE-cellulose." Further, they have reported that the organism accumulated $2 \sim 5.5 \mathrm{mg} / \mathrm{ml}$ of $\mathrm{CoA}$ in the culture broth. ${ }^{2,3)}$

The present report deals with the isolation and identification of $\mathrm{CoA}$ with the objective of large scale production.

\section{EXPERIMENTAL AND RESULTS}

\section{Materials}

The microorganism used was Brevibacterium ammoniagenes IFO 12071. DEAE-cellulose was provided from the Green Cross Corporation, Osaka. Phosphotransacetylase from Clostridium kluyveri was purchased from C. F. Boehringer \& Soehne GmbH, Mannheim, Germany. Other materials and chemicals were obtained from commercial sources.

\section{Analytical methods}

CoA was assayed by the method of Stadtman, Novelli, and Lipmann ${ }^{4}$ using the enzyme of Escherichia coli Crookes AKU 0001, and also by the method of Bergmeyer et $a l^{51}$ for the characterization of isolated products.

\footnotetext{
$\dagger$ Studies on the Metabolism of Pantothenic Acid in
} Microorganisms. Part V; for Part IV, see reference 3).
Total pantothenic acid was measured by the method of Novelli. ${ }^{6}$ ) Adenine content was determined by ultraviolet absorption in $0.1 \mathrm{~N}$ $\mathrm{HCl}$ using $E_{260_{\mathrm{nm}}}=15000$ as the standard value. Phosphorus was measured by the method of Allen ${ }^{7}$ and sulfhydryl by the method of Ellman. ${ }^{8}$

Paper chromatography was carried out by the ascending technique on Toyo Roshi No. 53 paper. The solvent systems used were I, isobutyric acid- $0.5 \mathrm{~N}$ ammonium hydroxide$0.1 \mathrm{M}$ tetrasodium ethylenediamine tetraacetic acid (100: 60: 1.6); II, ethanol-1 M ammonium acetate, $\mathrm{pH} 7.5$ (5:2). Paper electrophoresis was carried out on Toyo Roshi No. 53 paper impregnated with $0.2 \mathrm{M}$ acetate buffer, $\mathrm{pH} 3.5$, at $35 \mathrm{~mA} / 15 \mathrm{~cm}(4 \mathrm{KV})$ for $30 \mathrm{~min}$. Adeninecontaining compounds were located with a UV lamp. Phosphorus-containing compounds were located with Hanes and Isherwood spray ${ }^{9}$ followed by UV irradiation; sulfhydryl and disulfide compounds were detected with Toennies and Kolb spray. ${ }^{10}$

\section{Process}

1) Cultivation. Brevibacterium ammoniagenes IFO 12071 was cultivated aerobically for 5 days at $28^{\circ} \mathrm{C}$. The details of cultivation have been described in the preceding paper. ${ }^{3)}$ The culture filtrate (about $1000 \mathrm{ml}$ ) contained about $2.5 \mathrm{~g}$ of $\mathrm{CoA}$ as the disulfide form (or 
mixed disulfide forms) and some intermediates of CoA, such as pantothenic acid 4'-phosphate and pantetheine $4^{\prime}$-phosphate (disulfide or mixed disulfides), in high concentrations.

2) Purification. Initially the usual biochemical laboratory method was employed. The culture filtrate $(50 \mathrm{ml})$ was applied to a column of charcoal $(4 \times 4 \mathrm{~cm})$, and the substances adsorbed were eluted with $40 \%$ acetone containing $0.028 \%$ ammonia. CoAcontaining fractions were well separated from brown material (Fig. 1). Appropriate fractions containing $\mathrm{CoA}$ were combined, concentrated to a small volume $(50 \mathrm{ml})$ under reduced pressure, and 2-mercaptoethanol (17 $\mathrm{ml})$ was added. The mixture was left for $24 \mathrm{hr}$ at $10^{\circ} \mathrm{C}$, and then it was applied to a column of DEAE-cellulose (chloride form, $3 \times 18 \mathrm{~cm}$ ). Elution with $0.02 \mathrm{M} \mathrm{LiCl}$ in $0.003 \mathrm{~N} \mathrm{HCl}(1000 \mathrm{ml})$ removed 5'-adenylic acid (AMP), pantothenic acid 4'-phosphate, pantetheine $4^{\prime}$-phosphate, and adenosine 5'-diphosphate (ADP). Then, further elution was carried out by a $4000 \mathrm{ml}$ linear salt gradient $(0.03 \sim 0.1 \mathrm{M} \mathrm{LiCl}$ in $0.003 \mathrm{~N} \mathrm{HCl})$. For both the initial and gradient elutions 2-mercap-

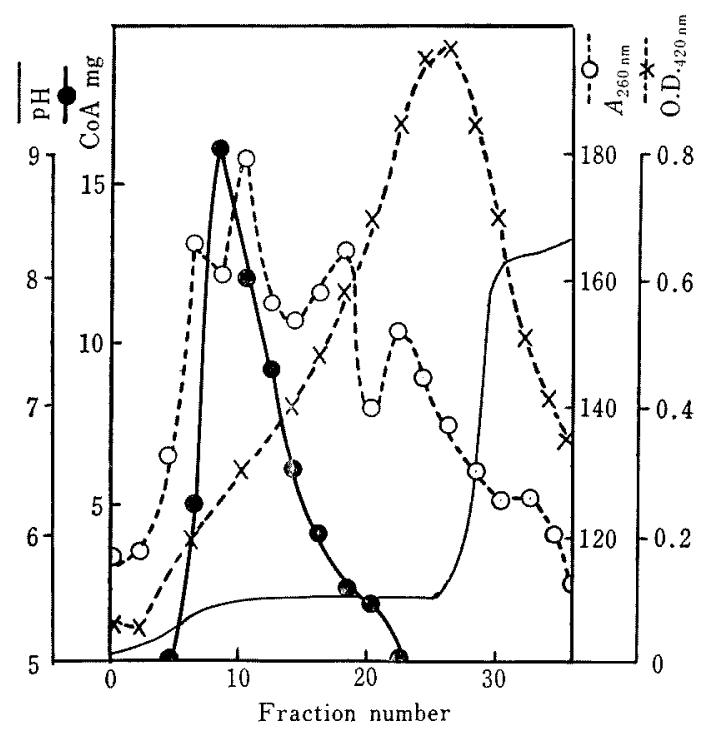

FIG. 1. Separation of CoA and Brown Material on a Charcoal Column.

Each fraction contains $10 \mathrm{ml}$ of eluate.

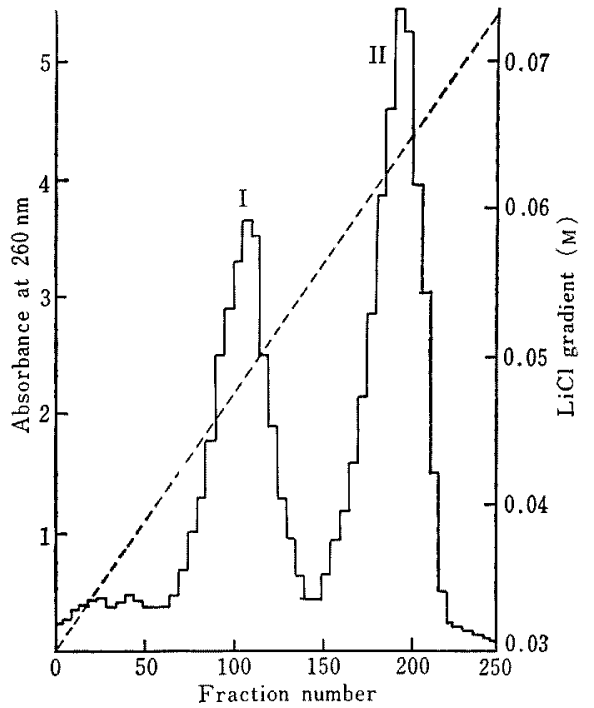

FIG. 2. Separation of CoA and ATP on a DEAECellulose Column Using a Linear Salt Gradient as Shown.

Each fraction contains $10 \mathrm{ml}$ of eluate. Peak I, CoA (thiol form); Peak II, ATP.

toethanol was present in the eluting solution at a concentration of $0.1 \%$. Two major ultraviolet-absorbing peaks were separated (Fig. 2). Peak I (CoA) was adjusted to $\mathrm{pH}$ 4.5 with $\mathrm{LiOH}$, and evaporated to dryness. The residue was dissolved in a small volume of methanol and the lithium salt of CoA was precipitated by the addition of 20 volumes of acetone. The salt was collected, and washed repeatedly with methanol-acetone (1:9). After drying over $\mathrm{P}_{2} \mathrm{O}_{5}$ in vacuo, the trilithium salt of $\mathrm{CoA}$ (thiol form) was obtained as a fine white powder $(40 \mathrm{mg})$.

The product was homogeneous with respect to ultraviolet absorption, sulfhydryl, and phosphorus, when chromatographed on paper. Venom phosphodiesterase digestion gave spots identical with adenosine $3^{\prime}, 5^{\prime}$-diphosphate and pantetheine 4'-phosphate. ${ }^{*}$ Anal. Calcd. for $\mathrm{C}_{21} \mathrm{H}_{33} \mathrm{O}_{16} \mathrm{~N}_{7} \mathrm{P}_{3} \mathrm{SLi}_{3} \cdot 8 \mathrm{H}_{2} \mathrm{O}$ : C, 27.13, $\mathrm{H}$, $5.37, \mathrm{~N}, 10.54 \%$. Adenosine: phosphorus: sulfhydryl: pantothenic acid, $1: 3: 1: 1$. Found: C, 27.01, H, 5.01, N, 10.30\%. Adenosine:

\footnotetext{
* Prepared by the method as described in a subsequent paper
} 
phosphorus: sulfhydryl: pantothenic acid, 1 : 3.03: 1.00: 0.99. UV $\lambda_{\max }^{0.1 \mathrm{NHCl}} \mathrm{nm} \quad 259$; UV $\lambda_{\max }^{0.1 \mathrm{NaOH}} \mathrm{nm} 260$. Assayed by the phosphotransacetylase method of Bergmeyer et al., the product showed a $101 \%$ activity on the basis of its adenosine content.

Peak II (ATP) was worked up as described above to give a lithium salt of ATP $(71.5 \mathrm{mg})$.

The product was homogeneous with respect to ultraviolet absorption and phosphorus when chromatographed on paper. The molar ratio of adenosine: phosphorus was $1: 3.10$ (Required, 1:3). UV $\lambda_{\max }^{0.1 \mathrm{NHCl}} \mathrm{nm} 259$; UV $\lambda_{\text {max }}^{0.1 \mathrm{NaOH}} \mathrm{nm} 260$.

Next, a large scale purification was carried out with the objective of application to industrial production; the scheme is diagramed in Fig. 3. The culture filtrate $(1000 \mathrm{ml})$ was passed through a column of Duolite S-30 $(3 \times 20 \mathrm{~cm})$ to remove brown material, and the column was washed with water $(100 \mathrm{ml})$. The solution passing through the column was directly applied to a column of charcoal $(5.5 \times 30 \mathrm{~cm})$, and the substances adsorbed were eluted with $40 \%$ acetone containing $0.028 \%$ ammonia. The eluted solution containing acetone was directly adsorbed to a column of Dowex $1 \times 2$ (chloride form, $5.5 \times$ $42.5 \mathrm{~cm}$ ). The products were eluted from the column with solutions of $\mathrm{LiCl}$ in $\mathrm{HCl}$. An example of the elution pattern is shown in Fig. 4. In each case appropriate fractions were combined, adjusted to $\mathrm{pH} 4.5$ with $\mathrm{LiOH}$, then concentrated to a small volume, and the lithium salt was isolated in the usual way. Yields were as follows: AMP, $127 \mathrm{mg}$ (Found: ratio of adenosine: phosphorus, 1:1.05; Required: 1:1). ADP, $604 \mathrm{mg}$ (Found: ratio of adenosine: phosphorus, 1: 2.15; Required: $1: 2$ ). ATP, $1212 \mathrm{mg}$ (Found: ratio of adenosine: phosphorus, $1: 3.11$; Required: 1:3). CoA disulfide, $1007 \mathrm{mg}$ (Found: ratio of adenosine: phosphorus: pantothenic acid, $1: 3.05: 0.90$; Required: $1: 3: 1$ ). This CoA disulfide contained a trace of a contaminating ultraviolet-absorbing compound ( $R f$ 0.19 in solvent I), when chromatographed on paper. Assayed by the phosphotransacetylase

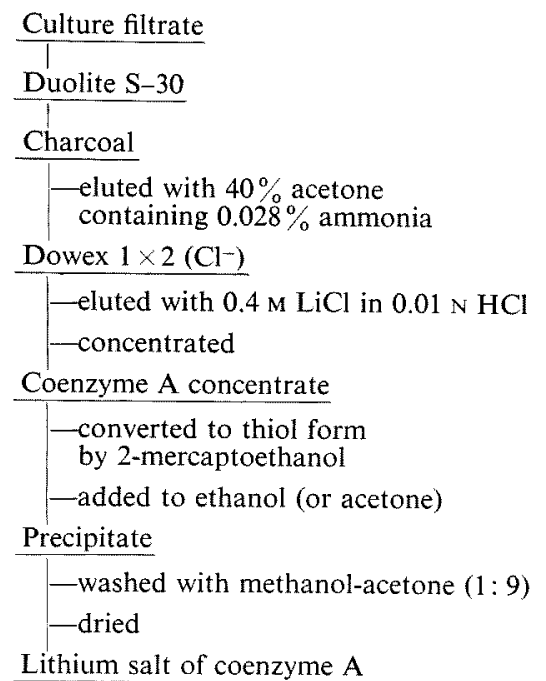

FIG. 3. Isolation of Coenzyme A from Culture Broth.

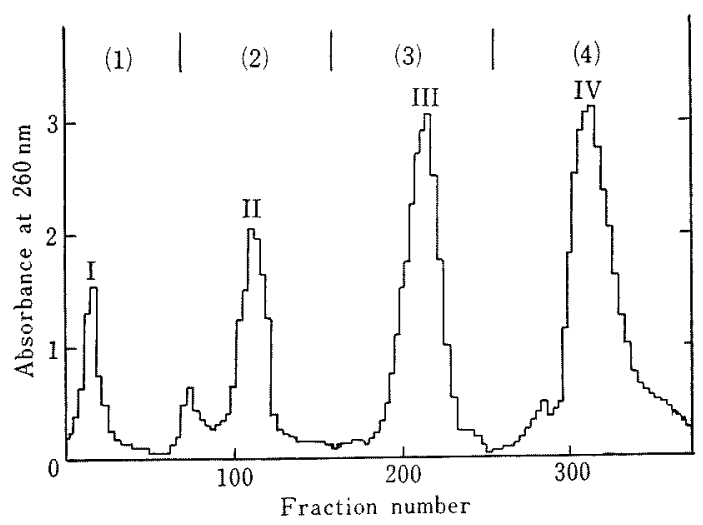

FIG. 4. A Typical Elution Pattern of Nucleotides in Culture Broth from a Dowex $1 \times 2$ Column (chloride form, $2.5 \times 25 \mathrm{~cm}$ ).

Nucleotides were eluted with (1) $0.01 \mathrm{~N} \mathrm{HCl}$, (2) $0.04 \mathrm{M}$ $\mathrm{LiCl}$ in $0.01 \mathrm{~N} \mathrm{HCl}$, (3) $0.2 \mathrm{M} \mathrm{LiCl}$ in $0.01 \mathrm{~N} \mathrm{HCl}$, and (4) $0.4 \mathrm{M} \mathrm{LiCl}$ in $0.01 \mathrm{~N} \mathrm{HCl}$. Each fraction contains $10 \mathrm{ml}$ of eluate. Peak I, AMP; Peak II, ADP; Peak III, ATP; Peak IV, COA (disulfide form).

method of Stadtman, Novelli, and Lipmann ${ }^{4}$ against purified $\mathrm{CoA}$ ( $92 \%$ by weight) standard, it showed $83 \sim 87 \%$ activity.

For the purpose of reduction, the above disulfide $(250 \mathrm{mg})$ was dissolved in water $(5 \mathrm{ml})$ and 2-mercaptoethanol $(5 \mathrm{ml})$ was added. The mixture was left for $24 \mathrm{hr}$ at $10^{\circ} \mathrm{C}$, adjusted to $\mathrm{pH} 4.5$ with $\mathrm{LiOH}$, and worked up as described above to give a lithium 
Table I. Paper Chromatography and PAPER EleCtrophoresis

\begin{tabular}{lrrr}
\hline \multirow{2}{*}{ Compound } & \multicolumn{2}{c}{$R f$} & $\begin{array}{c}\text { Electro- } \\
\text { phoresis }\end{array}$ \\
\cline { 2 - 3 } & \multicolumn{1}{c}{ I } & II & \\
\hline CoA (thiol form) & 0.57 & 0.16 & 18.5 \\
CoA (disulfide form) & 0.38 & 0.01 & 19.5 \\
AMP & 0.55 & 0.13 & 9.7 \\
ADP & 0.44 & 0.04 & 16.5 \\
ATP & 0.33 & 0.02 & 21.0 \\
\hline
\end{tabular}

a) Migration towards the anode is given in $\mathrm{cm}$.

salt (222 mg, Found: ratio of adenosine: phosphorus: sulfhydryl: pantothenic acid, 1: 3.07: 0.88:0.93; Required: 1:3:1:1), which was chromatographically shown to contain only reduced CoA and a little of the disulfide. Assayed by the phosphotransacetylase method of Bergmeyer et al., $\left.{ }^{5}\right)$ it showed an $84 \%$ activity on the basis of its adenosine content.

A further purified sample was obtained as the thiol form from the above disulfide by reduction with 2-mercaptoethanol followed by Dowex $1 \times 2$ (chloride form) column chromatography. The CoA reduced was eluted with $0.2 \mathrm{M} \mathrm{LiCl}$ in $0.01 \mathrm{~N} \mathrm{HCl}$ containing $0.1 \%$ 2-mercaptoethanol. The product was homogeneous with respect to ultraviolet absorption, phosphorus, and sulfhydryl on paper chromatography. Assayed by the phosphotransacetylase method of Bergmeyer et al., ${ }^{5}$ it now showed a $97 \%$ activity on the basis of its adenosine content.

\section{DISCUSSION}

CoA has been prepared by extraction from microorganisms ${ }^{1,12}$ and by chemical synthesis. $^{13 \sim 16)}$ However, these methods are not practical because of their lower yield or their intricacy. A new improved process with microorganisms has now been developed. Incubation of pantothenic acid, cysteine, and ATP with the dried cells of Brevibacterium ammoniagenes IFO 12071 gave $\mathrm{CoA}$ in a high yield. The product was isolated as the thiol form at a high level of purity by the use of charcoal and DEAE-cellulose. ${ }^{1)} \quad$ Further, cultivation of the organism with pantothenic acid, cysteine, AMP, and surfactant gave a higher accumulation of CoA $(2 \sim 5.5 \mathrm{mg} / \mathrm{ml})$ in the culture broth. ${ }^{3)}$ The product in the culture broth was purified by the use of Duolite S-30, charcoal, and Dowex $1 \times 2$, and isolated as the lithium salt in good yield.

As previously described, ${ }^{1 /}$ the product was directly isolated as the thiol form from the reaction mixture without prior separation of ATP, since the ATP in the reaction mixture was completely consumed for the CoA formation. On the other hand, in the present process it was necessary to remove ATP in order to obtain the product in high yield and high purity. Isolation of the product directly as the disulfide form rather than the thiol form brought a complete separation of ATP, and led to a considerably improved yield. The disulfide was readily converted to the thiol form by treatment with 2-mercaptoethanol. A further improved yield of CoA might be attained by recovering the mixed disulfide forms of $\mathrm{CoA}$ which might be present in the culture broth.

The present process is simple, rapid, and compact, and requires no special equipment. From a practical point of view, it possesses considerable advantages over any other microbial process previously reported ${ }^{11,12\}}$ in that the product can be purified in a higher yield with a compact plant, without complex purification procedures. This not only speeds up purification and isolation but also gives a highly purified product. Therefore, the present process would be suitable for industrial production.

A further practical point is that AMP, added as a precursor for CoA formation, can be recovered as ATP or ADP and the isolation of some CoA intermediates such as pantothenic acid 4'-phosphate and pantetheine $4^{\prime}$-phosphate is possible if necessary. In a similar process, these intermediates were obtained in higher yields, which will be described in a subsequent paper.

Acknowledgement. The authors wish to thank Drs. H. Yamada and K. Soda, Kyoto University, for their helpful advice during the course of this work. 
They also wish to thank the Institute for Chemical Research, Kyoto University, for the elemental analysis.

\section{REFERENCES}

1) K. Ogata, S. Shimizu and Y. Tani, Agr. Biol. Chem., 36, 184 (1972).

2) S. Shimizu, Y. Tani and K. Ogata, ibid., 36, 370 (1972).

3) S. Shimizu, K. Miyata, Y. Tani and K. Ogata, ibid., 37, 605 (1973).

4) E. R. Stadtman, G. D. Novellia nd F. Lipmann, J. Biol. Chem., 191, 365 (1951).

5) H. U. Bergmeyer, G. Holz, H. Klotzsch and G. Lang, Biochem. Z., 338, 114 (1963).

6) G. D. Novelli, "Methods of Biochemical Analysis," Vol. II, ed. by D. Glick, Interscience publishers, New York, N.Y., 1955, p. 209.

7) R. J. L. Allen, Biochem. J., 34, 858 (1940).

8) G. L. Ellman, Arch. Biochem. Biophys., 82, 70
(1959).

9) C. S. Hanes and F. A. Isherwood, Nature, 164, 1107 (1949).

10) G. Toennies and J. J. Kolb, Anal. Chem., 23, 823 (1951).

11) H. Beinert, R. W. von Kroff, D. E. Green, D. A. Buyske, R. E. Handschumacher, H. Higgins and F. M. Strong, J. Biol. Chem., 200, 385 (1953).

12) M. C. Reece, M. B. Donald, and E. M. Crook, J. Biochem. Microbiol. Technol. Eng., 1, 217 (1959).

13) J. G. Moffatt and H. G. Khorana, I. Am. Chem. Soc., 83, 663 (1961).

14) A. M. Michelson, Biochim. Biophys. Acta, 93, 71 (1964).

15) W. Gruber and F. Lynen, Ann., 659, 139 (1963).

16) M. Shimizu, O. Nagase, S. Okada, Y. Hosokawa, H. Tagawa, Y. Abiko and T. Suzuki, Chem. Pharm. Bull., 15, 655 (1967). 